Glaucoma

\title{
Is extreme surgery so extreme?
}

\section{Wong}

\section{The jury is out}

A t first sight, using retinectomy for treating glaucoma seemed extreme, even when most of the eyes treated were legally blind. More than 20 years ago, Robert Machemer described performing retinotomy to relieve traction in two patients with retinal detachment complicated by proliferative vitreoretinopathy (PVR). ${ }^{1}$ At the time retinotomy was considered extreme and surgically the last resort. Several years elapsed before small case series began to appear in literature..$^{2-5}$ By the time that the Silicone Oil Studies Report 5 was published in 1993, retinotomy was firmly established. ${ }^{6}$ The surprise was not only that gas and oil were equally effective, but that nearly one third of all patients in the study were treated with relieving retinotomy. One side effect of retinotomy was, of course, hypotony. ${ }^{7}$

The clearance of radioactive water from the vitreous in rabbit eyes was studied by Moseley et al in the early 1980s. ${ }^{8}$ Foulds and Damato made the observation that the retinal pigment epithelium was not necessary for retinal reattachment and that the bulk flow of water was sufficient to keep the retina apposed. ${ }^{9}$ It was Kirchhof, however, who went on to identify the neurosensory retina as the main barrier to water outflow in $1993 .{ }^{10}$ With the courage of his conviction, he went on to publish the use of retinotomy and retinectomy to lower intraocular pressure on the first nine patients in 1994. ${ }^{11}$ The latest report in this month's issue of the BJO ( $\mathrm{p} \mathrm{1094)}$ by Joussen et al demonstrated the safety and efficacy with a 5 year follow up.

Modifying wound healing has made important contributions to the success of glaucoma drainage surgery. ${ }^{12}$ Despite the use of antimetabolites, there are a number of patients with so called intractable glaucoma refractory to conventional surgical treatment. The retina, of course, does not heal in so far as defects do not close. ${ }^{11}$ Theoretically, rectinectomy should provide a predictable outflow. None the less, the results show hypotony in some patients but, more importantly, there was a significant complication rate in terms of retinal detachment and PVR. While the theory may be sound and the treatment valid, ultimately rectinectomy is complex surgery only achievable in relatively few hands. Cyclodiode treatment is readily available, easy to apply and perhaps associated with less frightening complications. ${ }^{13}$

\section{Rectinectomy is complex surgery only achievable in relatively few hands}

In the 1980s, there was a high prevalence of glaucoma among patients with retinal detachment and PVR treated with repeated vitrectomies and silicone oil. ${ }^{14}$ Since then, the number of glaucoma cases has fallen dramatically partly as a result of the use of high viscosity purified silicone oil, ${ }^{15}$ but partly also because of the increasing use of retinotomy and retinectomy. The recently finished British prospective trial of 5-FU and heparin for PVR showed that $53 \%$ of patients were treated with retinotomy and retinectomy (Charteris DG, The use of 5-FU and low molecular heparin as adjuvant to surgery for proliferative vitreoretinopathy: a prospective randomised control trial, 2003, in preparation). For patients with PVR at least, cutting the retina is more commonplace than extreme, often first line treatment rather than last resort. In that sense, we may all be using retinectomy for glaucoma. There is no doubt cutting the retina lowers the intraocular pressure. However, the jury is out on whether, in the long run, retinectomy is more controllable or "titratable" than cycloablation.

Br J Ophthalmol 2003;87:1057

\section{Author's affiliations}

D Wong, St Paul's Eye Unit, Royal Liverpool University Hospital, Liverpool L7 8XP, UK david.wong@medix-uk.com

\section{REFERENCES}

1 Machemer R. Retinotomy. Am J Ophthalmol 1981;92:768-74.

2 Machemer R, McCuen BW, de Juan E. Relaxing retinotomies and retinectomies. $\mathrm{Am} J$ Ophthalmol 1986:102:7-12.

3 Jacobs PM, Cooling RJ, Leaver PK, et al. Retinal relieving incisions. Eye 1987; 1 (Pt 4):500-3.

4 Federman JL, Eagle RC. Extensive peripheral retinectomy combined with posterior 360 degrees retinotomy for retinal reattachment in advanced proliferative vitreoretinopathy cases. Ophthalmology 1990:97: 1305-20.

5 Haut J, Larricart P, Geant G, et al. Circular subtotal retinectomy and inferior semicircular retinotomy. Material and results in 38 cases. Ophthalmologica 1986;192:129-34.

6 Blumenkranz MS, Azen SP, Aaberg T, et al. Relaxing retinotomy with silicone oil or long-acting gas in eyes with severe
proliferative vitreoretinopathy. Silicone Study proliferative vitreoretinopathy. Silicone Study
Report 5 . The Silicone Study Group. Am J Ophthalmol 1993;1 16:557-64.

7 Abrams GW, Azen SP, McCuen BW, et al. Vitrectomy with silicone oil or long-acting gas in eyes with severe proliferative vitreoretinopathy: results of additional and long-term follow-up. Silicone Study report 11. long-term follow-up. Silicone Study report
Arch Ophthalmol 1997; 1 15:335-44.

8 Moseley H, Foulds WS, Allan D, et al. Routes of clearance of radioactive water from the rabbit vitreous. $\mathrm{Br} J$ Ophthalmol 1984;68:145-51.

9 Foulds WS. Do we need a retinal pigment epithelium (or choroid) for the maintenance of retinal apposition? Br J Ophthalmo 1985;69:237-9

10 Kirchhof B, Ryan SJ. Differential permeance of retina and retinal pigment epithelium to water: implications for retinal adhesion. International Ophthalmology 1993;17:19-22.

11 Kirchhof B. Retinectomy lowers intraocular pressure in otherwise intractable glaucoma: preliminary results. Ophthalmic Surg 1994;25:262-7.

12 Khaw PT, Ward S, Porter A, et al. The long-term effects of 5 -fluorouracil and sodium butyrate on human Tenon's fibroblasts. Invest Ophthalmol Vis Sci 1992;33:2043-52.

13 Bloom PA, Tsai JC, Sharma K, et al. "Cyclodiode". Trans-scleral diode laser cyclophotocoagulation in the treatment of advanced refractory glaucoma. advanced refractory glaucoma.
Ophthalmology 1997; 104: 1508-19; discussion 1519-20.

14 Dimopoulos S, Heimann K. [Late complications following silicone injection. Long-term follow-up of 100 cases.] Klin Monatsbl Augenheilkd 1986;189:223-7.

15 Riedel KG, Gabel VP, Neubaver L, et al. Intravitreal silicone oil injection: complications and treatment of 415 consecutive patients. Graefes Arch Clin Exp Ophthalmol 1990;228: 19-23. 


\section{Therapy may yet stem from cells in the retina}

\section{R R Ali, J C Sowden}

\section{The eye is outstandingly well suited for the development of new treatments}

7 he paucity of effective treatments for inherited retinal disease and age related macular degeneration (AMD) underlines the need for the development of novel therapeutic approaches such as gene therapy. Luckily, the eye is outstandingly well suited for the development of new treatments. Non-invasive procedures for the determination of ocular structure and function in both the clinic and laboratory are better developed than for any other organ. Ease of access to the eye enables manipulation at all levels from subcellular to whole organ; the understanding of the eye, from developmental biology to biochemistry, is highly advanced and there are many established animal models of retinal disease. This has enabled rapid progress in the development of gene therapy approaches for retinal disease compared with that for other forms of neurological disorders. While there has been tremendous progress over the past 10 years with the development of gene therapy strategies, this approach will not be effective once degeneration has occurred and some form of cell transplantation may be required to enable the replacement of lost photoreceptor cells. The first trials of cell replacement have been performed using mature photoreceptors or their late progenitors as donor cells for transplantation into dystrophic mouse retinas. They have been shown to partially engraft and to survive for long periods in the host retina, but they fail to integrate efficiently within the host tissue. ${ }^{1}$ Alternative cell sources such as neural progenitor/stem cells have therefore been investigated.

Stem cells are the multipotent, self renewing cells that sit at the top of the lineage hierarchy. ${ }^{2}$ An archetypal stem cell is represented by the embryonic stem (ES) cell. ES cells are routinely derived from mouse blastocysts and, when introduced into host blastocysts, contribute to all adult tissues. Furthermore, ES cells can be induced to differentiate in vitro towards many cell lineages, including beating heart muscle cells, blood cells, neurons, glial cells, and adipocytes. ${ }^{3}$ Over the past few years, stem cells have also been isolated from adult tissues such as skin, blood, and only recently from liver and brain. In particular, adult neural stem (ANS) cells can be stably cultured in vitro and can be induced to differentiate into oligodendrocytes, astrocytes, and neurons. ${ }^{4}$ It has also been suggested that ANS cells have a very broad plasticity, and are capable of undergoing transdifferentiation to give rise to mature blood and muscle cells both in vitro and in vivo and this has prompted investigations into determining whether they might be used to replace missing photoreceptor cells.

The identification of human retinal stem cells is an important landmark that might ultimately lead to new treatments for retinal disease

A number of studies have examined the behaviour of brain derived neural progenitor cells transplanted into the mouse neural retina and assessed their potential for mediating retinal reconstruction. ${ }^{6-9}$ Survival and integration of such cells when transplanted into the retina has been observed. The greatest morphological integration and differentiation is observed after transplantation into younger eyes, ${ }^{10}$ but the failure to fully differentiate into retinal cells suggests either that appropriate cues are absent or that they already have some level of terminal commitment that precludes using them to replace lost photoreceptors. While it is well established that adult amphibians and fish and embryonic chicks regenerate their neural retina following loss of neurons, the mammalian eye is not known to regenerate. However, contrary to previous assumptions, in 2000, work in two laboratories demonstrated that the adult mouse retina contains progenitor cells in the ciliary margin that have stem celllike properties with the capacity to give rise to new photoreceptors, bipolar neurons, and Muller glia in vitro. ${ }^{11}{ }^{12}$ Perhaps these so called "retinal stem cells" when transplanted will have greater potential than brain derived neuronal progenitors to reconstitute a damaged retina.
In this issue of the BJO, Mayer et al ( $\mathrm{p}$ 1154) report the existence of nestin positive cells in adult human retina. Nestin immunoreactivity is a key indicator that these cells are neuronal progenitors. Although further studies, involving in vitro culture and differentiation of these cells, are required to determine whether they do indeed have stem cell-like properties, the data presented here would suggest that these cells may be retinal stem cells. Their location is consistent with the location of retinal stem cells in the mouse retina. More remarkable is the identification of nestin positive cells in epiretinal membranes from patients with proliferative vitreoretinopathy (PVR) with the implication that this newly identified cell type might be contributing to the disease. In order to proliferate and differentiate stem cells in vitro it is necessary to supplement the culture medium with growth factors. An intriguing possibility is that in patients with PVR just such a milieu may promote retinal stem cell proliferation, if not differentiation. The identification of human retinal stem cells is an important landmark that might ultimately lead to new treatments for retinal disease. It is obvious that an enormous amount of work will be required before therapies based on stem cell transplantation are tested in the clinic. Nevertheless, the groundwork required for such trials is now being established and as the first gene therapy trials for eye disease are being initiated 10 years after the first ocular gene transfer experiments in mice, we anticipate that progress in this field will be as rapid and exciting.

The key challenge is now to provide appropriate developmental cues to induce re-enactment of photoreceptor development in the mature retina by determining the local cues and transcription factors required for in vivo expansion, integration, and differentiation of retinal stem cells in order to repair a degenerating retina. A number of growth factors have been identified that are capable of promoting progenitor proliferation and differentiation, along with the expression of some of the critical genes controlling cell commitment and differentiation during retinal development. ${ }^{13} 14$ Stimulation of these pathways is likely to be the key to activating retinal repair from transplanted retinal progenitors.

Br J Ophthalmol 2003;87:1058-1059

\section{Authors' affiliations}

R R Ali, Institute of Ophthalmology, University College London, Bath Street, London ECIV 9EL, UK

R R Ali, J C Sowden, Institute of Child Health, University College London, Guilford Street, London WCIN 1EH, UK 
Correspondence to: Robin R Ali, Institute of Ophthalmology, University College London, Bath Street, London EC IV 9EL, UK;

r.ali@ucl.ac.uk

\section{REFERENCES}

1 Kwan AS, Wang S, Lund RD. Photoreceptor layer reconstruction in a rodent model of retinal degeneration. Exp Neurol 1999.59.21-33.

2 Fuchs E and Segre JA. Stem cells: a new lease on life. Cell 2000;100:143-55.

3 Watt FM, Hogan BL. Out of Eden: stem cells and their niches. Science 2000;287:142730.

4 Weiss S, Reynolds BA, Vescovi AL et al. Is there a neural stem cell in the mammalian forebrain? Trends Neurosci 1996;19:387-93

5 Galli R, Borello U, Gritti A, et al. Skeletal myogenic potential of human and mouse neural stem cells. Nat Neurosci 2000:3:986-91.

6 Takahashi M, Palmer TD, Takahashi J, et al. Widespread integration and survival of adult-derived neural progenitor cells in the developing optic retina." Mol Cell Neurosci 1998; 12:340-8.

7 Chacko DM, Rogers JA, Turner JE, et al. Survival and differentiation of cultured retina progenitors transplanted in the subretinal space of the rat. Biochem Biophys Res Commun 2000;268:842-6.

8 Young, W, Ray J, Whiteley SJ et al. Neuronal differentiation and morphological integration of hippocampal progenitor cells transplanted to the retina of immature and mature dystrophic rats. Mol Cell Neurosci 2000; 16:197-205

9 Akita J, Takahashi $M$, Hojo $M$, et al. Neuronal differentiation of adult rat hippocampus-derived neural stem cells transplanted into embryonic rat explanted retinas with retinoic acid pretreatment. Brain Res 2002;954:286-93

10 Van Hoffelen SJ, Young M, Shatos MA, et al. Incorporation of murine brain progenitor cells into the developing mammalian retina. Invest Ophthalmol Vis Sci 2003;44:426-34.

11 Tropepe V, Coles BL Chiasson BJ, et al. Retinal stem cells in the adult mammalian eye. Science 2000;287:2032-6.

12 Ahmad I, Dooley CM, Thoreson WB, et al. In vitro analysis of a mammalian retinal progenitor that gives rise to neurons and glia. Brain Res 1999;831:1-10.

13 Levine EM, Fuhrmann S, Reh TA. Soluble factors and the development of rod photoreceptors. Cell Mol Life Sci 2000;57:224-34.

14 Dyer MA, Cepko CL. Regulating proliferation during retinal development. Nat Rev Neurosci $2001 ; 2: 333-42$

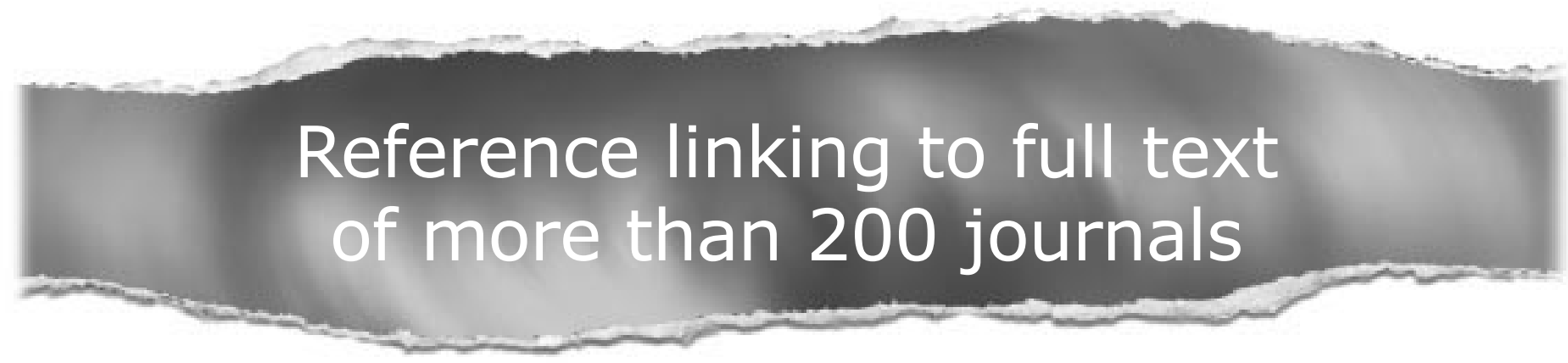

\section{Toll free links}

You can access the FULL TEXT of articles cited in the British Journal of Ophthalmology online if the citation is to one of the more than 200 journals hosted by HighWire (http://highwire.stanford.edu) without a subscription to that journal.

There are also direct links from references to the Medline abstract for other titles.

www.bjophthalmol.com 